This item is the archived peer-reviewed author-version of:

\title{
Airway necrosis and barotrauma after ecstasy inhalation
}

\section{Reference:}

Van den Kerckhove Evi, Roosens Laurence, Siozopoulou Vasiliki, Verbrugghe Walter, Aerts Jelle, Huyskens Jef, Raemen Hannelore, Jorens Philippe.- Airway necrosis and barotrauma after ecstasy inhalation

American journal of respiratory and critical care medicine - ISSN 1073-449X - New york, Amer thoracic soc, 196:1(2017), p. 105-106

Full text (Publisher's DOI): http://dx.doi.org/doi:10.1164/RCCM.201612-2416IM

To cite this reference: http://hdl.handle.net/10067/1448550151162165141 
IMAGES IN PULMONARY, CRITICAL CARE, SLEEP MEDICINE AND THE SCIENCES

Airway necrosis and barotrauma after ecstasy (MDMA) inhalation.

Evi Van den Kerckhove ${ }^{1}, \mathrm{MD}$, Laurence Roosens ${ }^{2}, \mathrm{PhD}$, Vasiliki Siozopoulou ${ }^{3}, \mathrm{MD}$, Walter Verbrugghe ${ }^{1}, M D$, Jelle Aerts ${ }^{4}, M D$, Jef Huyskens ${ }^{5}, M D$, Hannelore Raemen ${ }^{6}, M D$, Philippe G Jorens ${ }^{1}, \mathrm{MD}, \mathrm{PhD}$.

From the departments of Critical Care Medicine ${ }^{1}$, Clinical Biochemistry and analytical Toxicology ${ }^{2}$, Pathology ${ }^{3}$, Respiratory Medicine ${ }^{4}$, Radiology $^{5}$ and Emergency Medicine ${ }^{6}$, Antwerp University Hospital, University of Antwerp, Edegem, Belgium

\section{Running title: MDMA inhalation causes airway necrosis}

Key words: tracheal necrosis, pneumomediastinum, barotrauma, crystals, amphetamines, ecstasy, MDMA (methylenedioxyamphetamine)

\#Corresponding author mailing address: Philippe G Jorens, MD, Ph D, Department of Critical Care Medicine, Antwerp University Hospital, University of Antwerp, Wilrijkstraat 10, B-2650 Edegem, Belgium

Phone: 32-3-8213639.

Fax: $\quad 32-3-8284882$.

E-mail: Philippe.Jorens@uza.be

All authors disclose all financial and personal relationships that could be viewed as presenting a potential conflict of interest. 
A 25-year old man was found unresponsive. Resuscitative measures were not initiated until emergency personnel arrived. Asystole was observed and he was intubated after only one attempt. During intubation aspiration occurred. Return of spontaneous circulation was seen 30 minutes after initiation of good quality cardiopulmonary resuscitation. Initial blood gases at the emergency department showed an arterial $\mathrm{pH}$ of 6.8 with a lactate of $12 \mathrm{meq} / \mathrm{l}$ (normal value $<1.5$ ). Rapid ultrasound assessment did not identify acute intrathoracic or intraabdominal pathology. CT showed brain edema and diffuse alveolar infiltrates of both lungs. No pneumothorax or pneumomediastinum was seen. Cardiac catheterization showed no anomalies. Routine toxicological analysis and semi-quantification by liquid chromatography-mass spectrometry revealed the presence of approximately $1 \mathrm{mg} / \mathrm{ml}$ ecstasy/3,4-Methylenedioxy-methamphetamine (MDMA) in the urine. He was known as a sporadic user of ecstasy by inhalation.

Twelve hours after admission to the intensive care unit, he developed extensive subcutaneous emphysema of the thorax and neck. Lung protective ventilation had been instituted and no central subclavian venous line had been inserted. A chest X-ray and CT showed a pneumomediastinum and bilateral pneumothoraces (Figures $1 \mathrm{~A}$ and B). Bilateral chest tubes were inserted. A bronchoscopy showed extensive tracheal and bronchial inflammation and necrosis, but no macroscopic airway rupture (Figure 2). Airway biopsies showed widespread necrosis, neutrophil infiltration and crystals (Figure 3A). The same crystals were found in the bronchial aspirate and mini-bronchoalveolar lavage (BAL) fluid (Figure 3B). A gastroscopy did not reveal esophageal rupture or necrosis of the stomach.

Analysis of a white powder found in his trousers' pouch $(\mathrm{pH} \mathrm{4)}$ and BAL fluid revealed the presence of MDMA. The bronchial biopsies (Figure 3A), BAL-fluid (Figure 3B), urine as well as powder (Figure 3C) all showed massive amounts of identical crystals. The patient was declared brain dead later on and after consent, liver and kidney donation was executed. An autopsy was denied.

The amphetamine MDMA causes activation of the sympathetic autonomic nervous system with vasoconstriction, fever, organ failure and cardiac arrest (1). In this patient, its use led to hypoxic cardiac arrest and later on barotrauma. Pneumomediastinum, pneumopericardium, and pneumothorax have been associated with drugs activating the sympathethic nervous 
system such as inhaled cocaine (1) or amphetamines usage in case series or reports (2-5). For MDMA, barotrauma has been reported mainly after oral intake $(1,2)$, and only thrice after MDMA inhalation (3-5). The mechanism after oral intake is likely due to Valsalva maneuvers during physical exertion at parties $(1,2)$. Inhaling deeply with repeated Valsalva maneuvers prior to exhaling against pursed lips is believed to be the cause in inhalation drug users (1). In this case, pneumothoraces were likely related to massive airway necrosis due to vasoconstriction of airway wall vessels after local exposure, through inhalation or ingestion and aspiration, to an acidic preparation containing the powerful vasoconstrictor MDMA. To our knowledge this is the first report on MDMA detection in the aspiration fluid from lungs and causing widespread bronchial necrosis.

References:

1) Tseng W, Sutter ME, Albertson TE. Stimulants and the lung: review of literature. Clin Rev Allergy Immunol. 2014 Feb;46(1):82-100.

2) Marasco SF, Lim HK. Ecstasy-associated pneumomediastinum. Am R Coll Surg Engl 2007; 89(4): 389-393.

3) Le Floch AS, Lapostolle F, Danhiez F, Adnet F. Pneumomediastinum as a complication of recreational ecstasy use. Ann Fr Anesth reanim 2002; 21(1):35-7.

4) Mutlu H, Silit E, Pekkafali Z, Incedayi M, Başekim C, Kizilkaya E. Ecstasy'(MDMA)induced pneumomediastinum and epidural pneumatosis. Diagn Interv Radiol. 2005; 11(3):150-1.

5) Bernaerts A, Verniest T, Vanhoenacker F, Van den Brande P, Petré C, De Schepper AM. Pneumomediastinum and epidural pneumatosis after inhalation of "Ecstasy". Eur Radiol. 2003; 13(3):642-3. 
Figure legends:

Figure 1A: Anteroposterior radiographs of the thorax (from left to right: at admission, 2 hours and 17 hours after admission showing progressive congestion or pulmonary edema in both lungs. The 3rd radiograph shows a pneumothorax of the apical part of the left lung. Sharp contours of heart and mediastinum, suggestive for extensive pneumomediastinum. Subcutaneous emphysema in the neck and air under the diaphragm. Central venous line in the right internal jugular vein extending into the superior vena cava. Intubation tube in the trachea.

Figure 1B: CT scan of the thorax: thin-slice $1,25 \mathrm{~mm}$ axial and $11 \mathrm{~mm}$ average coronal reconstructions in lung window: Diffuse areas with ground glass opacities in both lungs with a predominantly central distribution, suggestive for pulmonary alveolar edema, where most of the fluid is in the alveolar space. Extensive pneumomediastinum with dissection of the air to the paracardial and preperitoneal area and to the neck. Pneumothorax on the right side. Thoracic drain on the left side.

Figure 2: Bronchoscopic view of the bronchus intermedius (right upper lobe): Extensive bronchial inflammation and necrosis with purulent secretions.

Figure 3. identification of ecstasy/MDMA crystals.

Figure 3A: HE,40x: Identification of birefringent crystals under polarization in the bronchial biopsy

Figure 3B: Cross polarization microscopy (200x enlargement): crystals in bronchoalveolar lavage fluid

Figure 3C: Cross polarization microscopy (250x enlargement): crystalline powder 


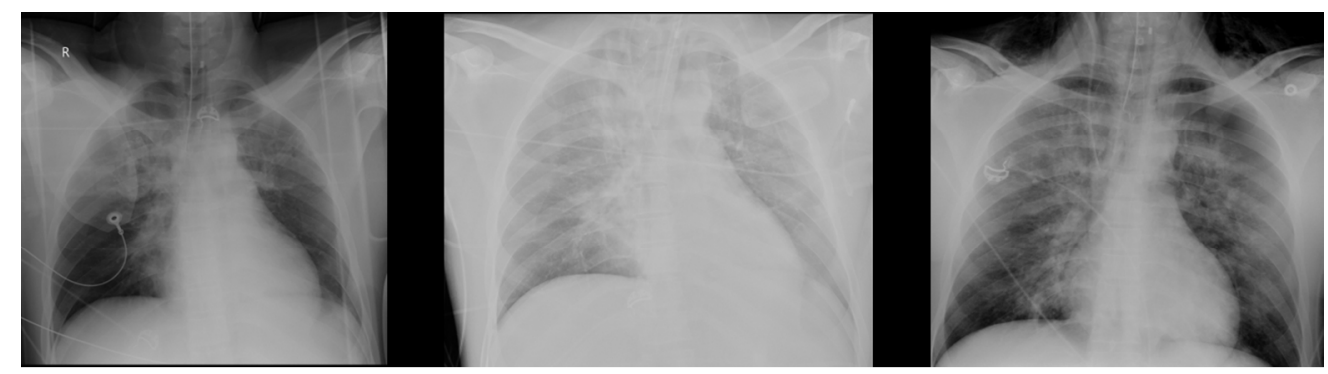

Figure 1A: Anteroposterior radiographs of the thorax (from left to right: at admission, 2 hours and 17 hours after admission showing progressive congestion or pulmonary edema in both lungs. The 3rd radiograph shows a pneumothorax of the apical part of the left lung. Sharp contours of heart and mediastinum, suggestive for extensive pneumomediastinum. Subcutaneous emphysema in the neck and air under the diaphragm. Central venous line in the right internal jugular vein extending into the superior vena cava. Intubation tube in the trachea.

$244 \times 66 \mathrm{~mm}(150 \times 150 \mathrm{DPI})$ 


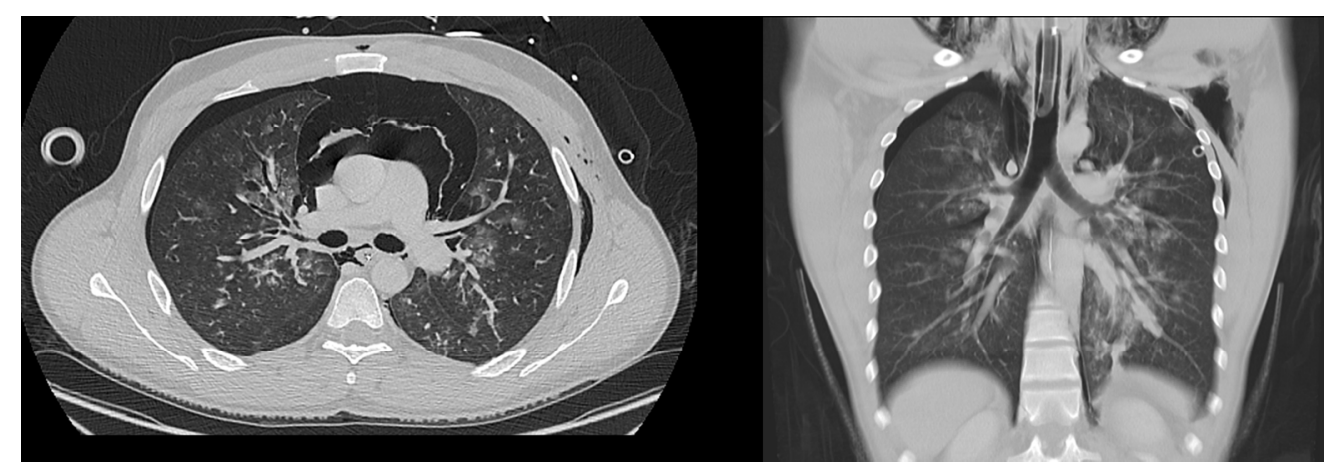

Figure 1B: CT scan of the thorax: thin-slice $1,25 \mathrm{~mm}$ axial and $11 \mathrm{~mm}$ average coronal reconstructions in lung window: Diffuse areas with ground glass opacities in both lungs with a predominately central distribution, suggestive for pulmonary alveolar edema, where most of the fluid is in the alveolar space. Extensive pneumomediastinum with dissection of the air to the paracardial and preperitoneal area and to the neck. Pneumothorax on the right side. Thoracic drain on the left side. Intubation tube in the trachea.

$285 \times 97 \mathrm{~mm}(150 \times 150 \mathrm{DPI})$ 


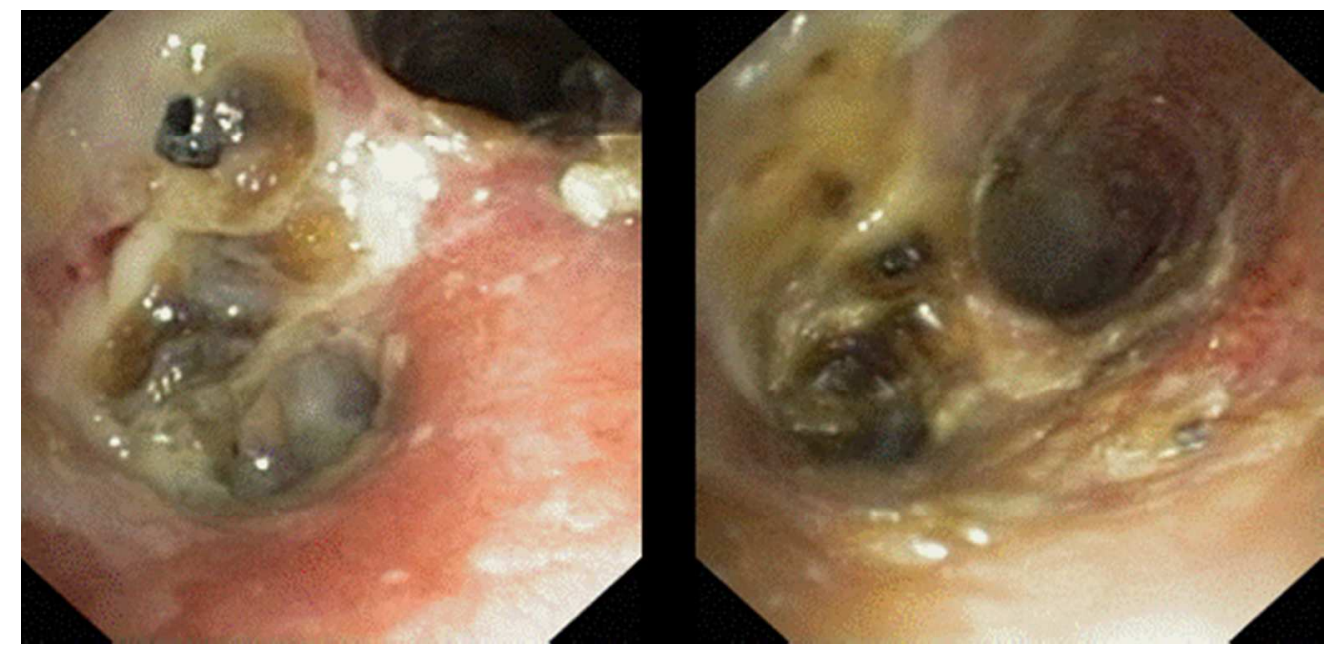

Figure 2: Bronchoscopic view of the bronchus intermedius (right upper lobe): Extensive bronchial inflammation and necrosis with purulent secretions.

$135 \times 65 \mathrm{~mm}(96 \times 96 \mathrm{DPI})$ 


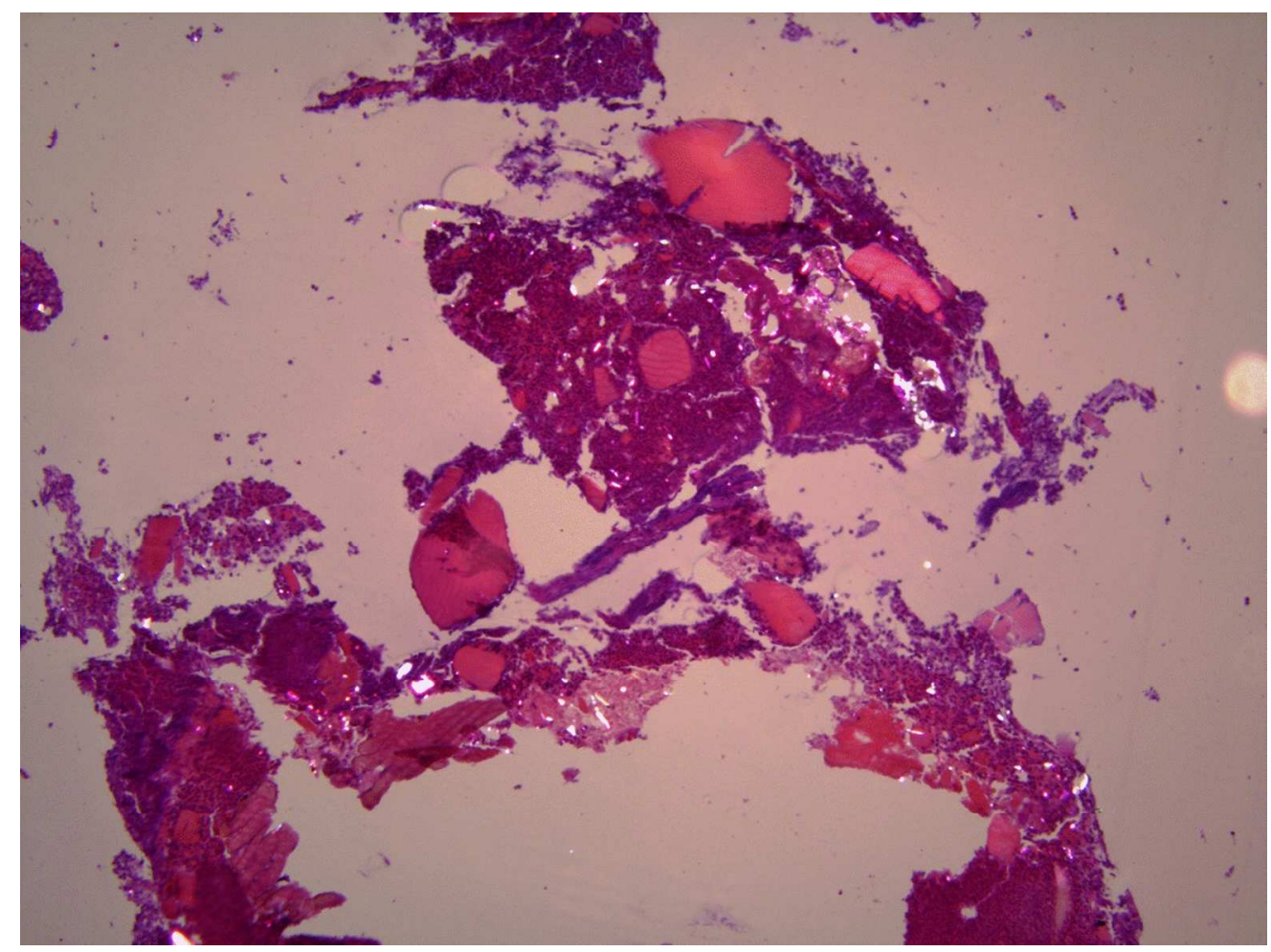

Figure 3. identification of ecstasy/MDMA crystals.

Figure 3A: $\mathrm{HE}, 40 \mathrm{x}$ : Identification of birefringent crystals under polarization in the bronchial biopsy

$366 \times 274 \mathrm{~mm}(96 \times 96 \mathrm{DPI})$ 


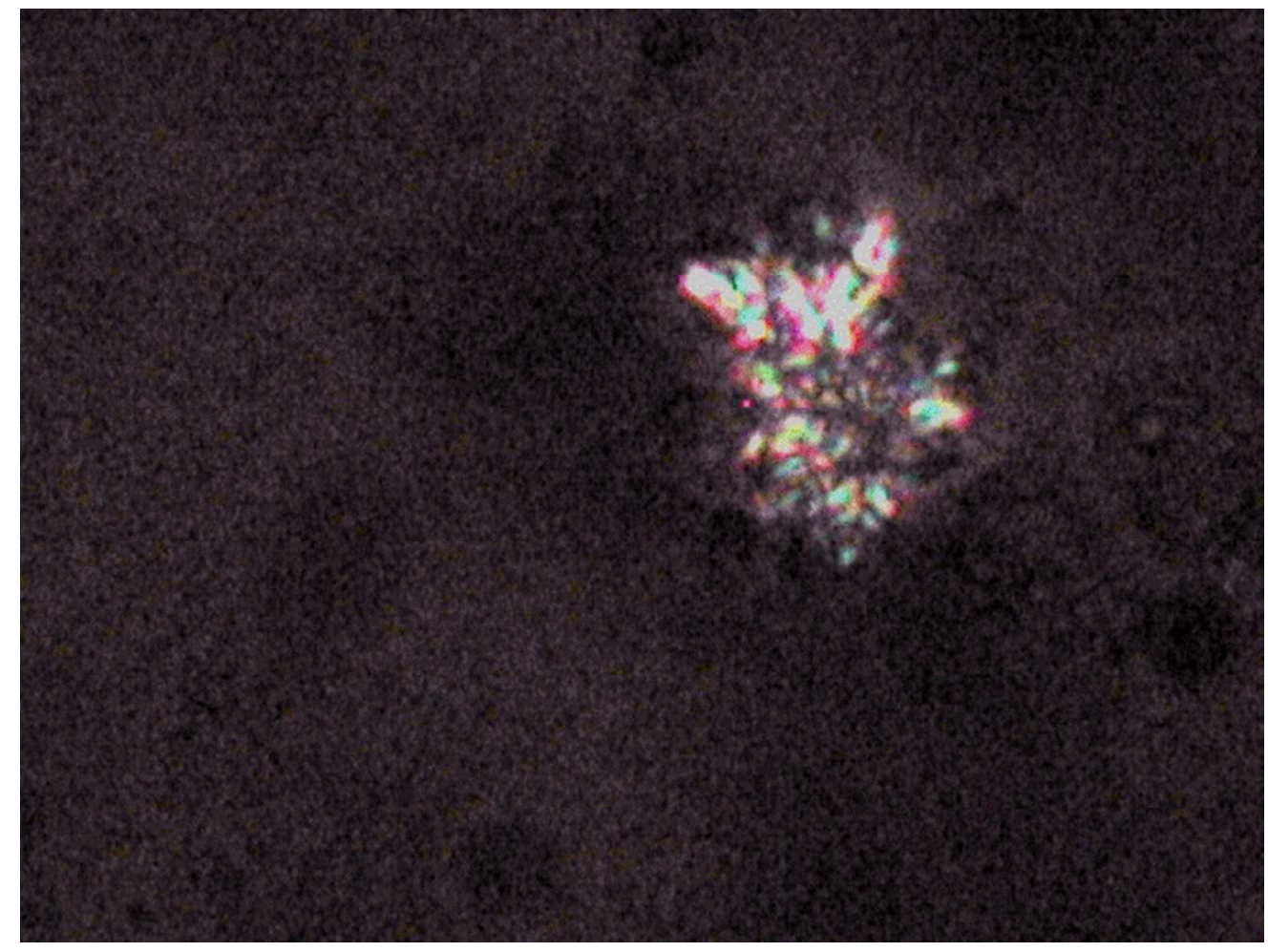

Figure 3. identification of ecstasy/MDMA crystals.

Figure 3B: Cross polarization microscopy (200x enlargement): crystals in bronchoalveolar lavage fluid

$189 \times 142 \mathrm{~mm}(96 \times 96 \mathrm{DPI})$ 


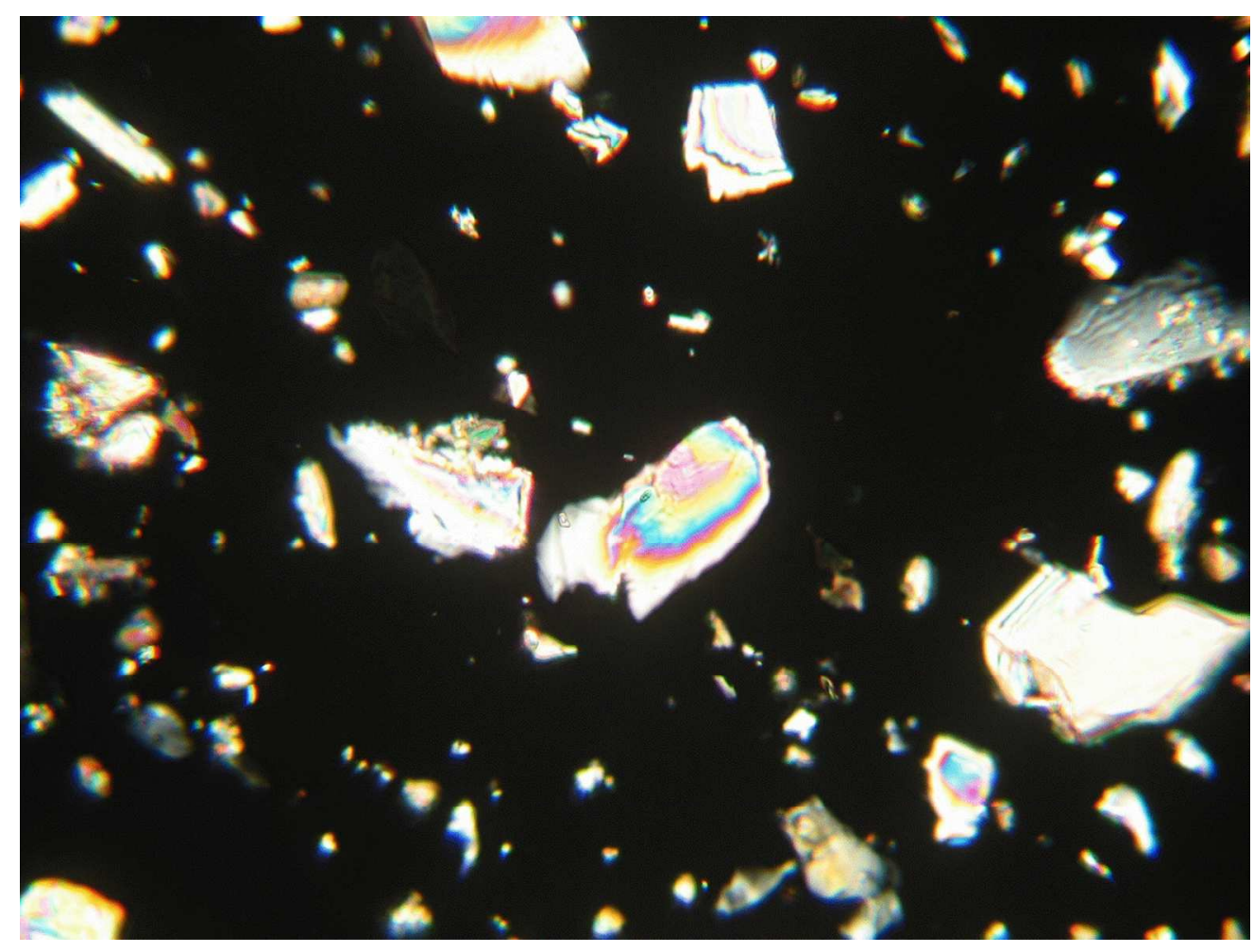

Figure 3. identification of ecstasy/MDMA crystals.

Figure 3C: Cross polarization microscopy (250x enlargement): crystalline powder $366 \times 274 \mathrm{~mm}(96 \times 96$ DPI $)$ 